\title{
Maxillary Sinus Adenoid Cystic Carcinoma
}

National Cancer Institute

\section{Source}

National Cancer Institute. Maxillary Sinus Adenoid Cystic Carcinoma. NCI Thesaurus.

Code C6239.

An adenoid cystic carcinoma that arises from the maxillary sinus. It usually has an aggressive clinical course. 